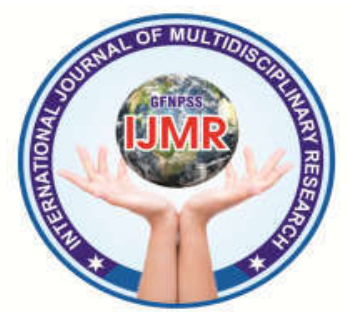

\title{
A DESCRIPTIVE STUDY TO ASSESS THE KNOWLEDGE REGARDING MALARIA AND IT'S PREVENTION AMONG STUDENTS STUDYING IN SELECTED MIDDLE SCHOOL AT JAIPUR WITH A VIEW TO DEVELOP AN INFORMATION BOOKLET
}

\author{
PUSHPENDRA KUMAR \\ Lecturer, Tagore Nursing College, Jaipur Rajasthan \\ Corresponding Email :- 11kumarpushpendra@gmail.com
}

\section{ABSTRACT}

Introduction :- Malaria is one of the most common infectious disease and a great public Health problem worldwide, particularly in Africa and south asia. About 3 billion are at risk of infection in 109 countries each year, there are an estimated 250 million cases of malaria leading to approximately 1 million death mostly in children under 5 year of age. ${ }^{[39]}$

The disease affects all age groups, especially the poor, the pregnant mothers and children under-five years of age. The high risk group are children under-five years of age. Malaria kills 3000 under-five children every day throughout the world .

Material and methods : Descriptive research design used in this study . purposive sampling technique was used to selected the samples. 100 middle school students were included in this study . The data was collected and organized for data analysis.

Results: Over all knowledge of middle school students regarding malaria and its prevention shows that $41.40 \%$ with SD of 1.36 in the aspect of knowledge regarding Introduction of malaria 39.50\%with SD 1.65 regarding Epidemiological aspects , 42\% with SD 1.76 regarding clinical manifestation $28 \%$ with SD .45 regarding Investigation , 46\%with SD 2.68 regarding prevention and malaria .

Conclusion: The level of knowledge of students studying in selected middle school regarding malaria and it's prevention shows that 33\% of students have poor knowledge ,23\% have average knowledge , 21\% have good knowledge and 23\% very good .

Keywards : knowledge, Prevention, malaria, middles school students 


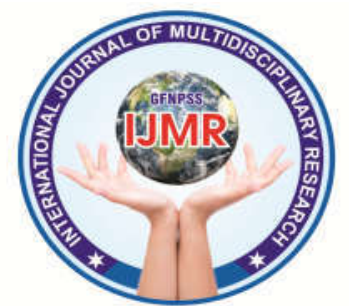

\section{.Background of the study}

"Millions of lives could be saved by using knowledge what we have today. The challenge is to transform this knowledge into action".

Health is a fundamental human right and it is the responsibility of the government to provide health care in equal proportions. Ever since India's independence in 1947 various national health schemes and programmes have been launched with a view to improve the health status of peoples living in rural area. ${ }^{[1]}$

Among the many health problems in India, communicable disease is the major health problems which are transmitted to man by direct and indirect contact with the causative agent. The disease which indirectly transmitted by mosquito are dengue, malaria, filaria and chikungunya among these disease malaria is one of the common disease in the community ${ }^{[2]}$

Malaria has been a major health problem, was recognized by roman and Greek. Who associate it with swampy area. They postulated that intermittent fever where due to "bed odour" coming from the marshy area and thus gave the name malaria ( mal =bad+air $)$ to intermittent fever today the causative organism is known the name has struck to this disease. ${ }^{[3]}$

In 18 th century people believed that Malaria is occurred due to mal-air i.e. bad air from which the word Malaria is derived. Malaria is one of the oldest recorded diseases in the world. In 1880, Laveran a French army surgeon discovered the Malaria parasite in Algiers, North Africa. Sir Ronald Ross, in 1897 while working at Secunderabad in Andhra Pradesh, India discovered that. Malaria is transmitted by Anopheline mosquito for which he received noble prize. ${ }^{[4]}$

Malaria is a protozoal disease caused by infection with parasites of the genus plasmodium and transmitted by some species of infected Anopheline mosquito. Ross found Malaria parasites growing as cysts in the stomach wall of Anopheline mosquito which had previously fed on Malaria client ${ }^{[4]}$

Malaria is one of the most common infectious disease and a great public health problem worldwide, particularly in Africa and south asia. About 3 billion are at risk of infection in 109 countries each year, there are an estimated 250 million cases of malaria leading to approximately 1 million 


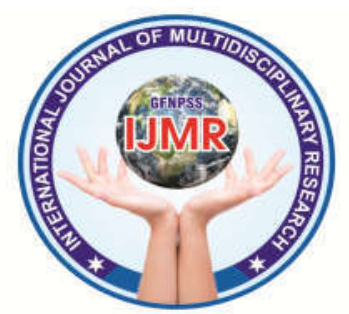

death mostly in children under 5 year of age. $^{\text {[39] }}$

The disease affects all age groups, especially the poor, the pregnant mothers and children under-five years of age. The high risk group are children under-five years of age. Malaria kills 3000 under-five children every day throughout the world ${ }^{[5]}$

The national malaria control programme was lauched in april 1953 .which was upgraded to national malaria eradication programme [NMEP] in 1958. The NMEP achieved remarkable success during the period 1958-1965, by which time the incidence of malaria control requires an integrated approach comprising prevention including vector control and treatment with effective antimalaria. $^{[42]}$

Malaria is a tropical disease passed on to human by mosquitoes. Malaria is a spead by the female of the anopheles species of mosquito, when one of these mosquitoes bite you. It feed on your blood and injects malaria parasites into your body .it only takes one bite to infect you. in some form of malaria parasites .can stay dormant in your body for year occasionally Walking up and causing you to have more attack of malaria ${ }^{[41]}$
At present about 100 countries in the world are considered as malarious. Worldwide more than 2.4 billion population are still at risk. The incidence of Malaria is estimated to be 300 to 500 million cases each year, about 90 per cent of this occurring in sub-Saharan Africa and mostly caused by Plasmodium Falciparum. Every year one million deaths are occurred among children under - five years. These childhood deaths are occurred mainly from Cerebral Malaria and Anemia, which constitutes nearly twenty five per cent of child mortality in Africa. Among hospitalized children with severe Malaria 10 to 30 percent of fatality rates have been reported. ${ }^{[5]}$

Prevention is better than cure. Prevention and information is the key to prevent and control Malaria. Various preventive strategies were developed to prevent and control Malaria. Malaria control programme was launched by WHO in 1948. By 1951 WHO was actively involved in Malaria control projects, mainly in Asia. By 1955 the number of Malaria cases worldwide had dropped by at least one third. The World Health Assembly in 1955 has taken up Malaria eradication programme as an international 


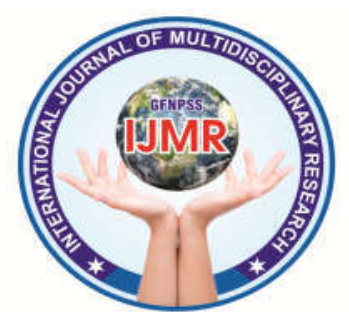

objective. This programme began to lose momentum because of major setbacks. World Health Assembly again launched Malaria control programme where eradication was an impracticable. ${ }^{[4]}$

Malaria is a one of the major health problem in the developing countries recent estimate indication that between 300-500 million. Clinical cases and between 1.52.7 million death due to it .occure world wide annually, $90 \%$ of which occure in tropical Africa it is estimated that 1.2 billon people out of the 1.4 billion people live in malarious area 1995. Were estimated at 21.9 million with almost 32000 death in India ${ }^{[43]}$

According to the world malaria report 2017, in the year 2016, more than half of the population [698] was at risk of malaria the report estimated the total cases in india at 1.31 million and death at 23990 [43]

\section{METHODS OF DATA COLLECTION}

\section{Setting of the study}

Selected middle school of rural community at Jaipur

\section{Population}

"An aggregate or totality of all subjects, that possess a set of specification"
The target population is the group of population that the researcher aims to study and to whom the study findings will be generalized, the target population comprises of all the middle school students.

The population for the present study comprised of the middle school students in selected middle school .

\section{SAMPLE:}

Sample refers to subset of the population that is selected to participated in a particular study .

In this study the sample consist of middle school students who ful filled the inclusion criteria

\section{SAMPLE SIZE :}

A sample size is a small portion of a population selected for the study .it consistutes a subsets of total population . the sample of the presented study comprised of 100 middle school students who met inclusion criteria were selected for the study .

\section{Sampling techniques}

Sampling is the process in which representative units of a population are selected for study in a research investigation .

Non-probability sampling is where sample are selected based on the judgment of the 


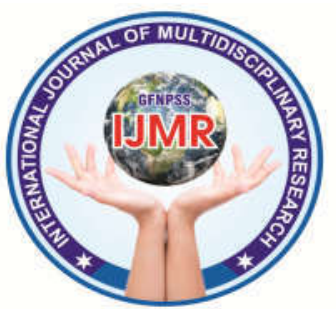

researcher to achieve particular objectives of the research at hand.

Purposive sampling technique is a strategy in which the researcher's knowledge of the population and its elements used to select sample which are typical to the population.

Purposive sampling technique, a type of nonprobability sampling approach was used to select the sample of 100 middle school students .

\section{Inclusion criteria-}

- Middle school students who are willing to participate in the study .

- Middle school students who are presence at the time of during data collection .

\section{Exclusion Criteria-}

- Students studying in other classes .

\section{SELECTION AND DEVELOPMENT}

\section{OF TOOL:-}

\section{SELECTION OF THE TOOL:-}

The instrument selected in research must br the vehicle to obtain the best data for drawing conclusion of the study.

A structured knowledge questionnaire schedule was selected on the basis of the objective of the study, as it was considered to be the most appropriate instrument to elicit responses from the middle school students .

\section{DEVELOPMENT OF THE TOOL:-}

The following steps were carried out in the preparation of the instrument

$>$ Related literature was reviewed in preparation of the instrument.

$>$ Guidance and consultation of the nursing expert and medical expert were taken for the construction of instrument.

$>$ Based on conceptual framework.

$>$ Based on the consultation with subject expert.

\section{DESCRIPTION OF THE TOOL:-}

Data collection tools are procedure or instrument used by the researcher to observe or measure the key variable in the research problem. The instrument used in the study consisted of two sections.

Part I:- Demographic variables of middle school students. It consist of 8 items regarding age, gender , religion, educational of mother, type of family, occupation of father, any case of malaria in family or neighbourhoods and any

previous knowledge regarding malaria Part II:- It consist of 30 items regarding 


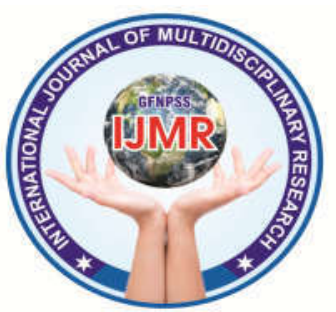

malaria and its prevention which were divided into 5

\section{SCORE INTERPETATION}

Part II consist of knowledge items including 30 objective types of multiple choice questions with 5 distracters. All questions had only one correct answer. Each correct response was awarded a single score according to the predetermined key and zero score was awarded to wrong responses and omissions. Total possible maximum score for all the items were 30 . This tool, which was in English, was translated into Hindi. Therefore the same translated version was used for the interview method. The score was converted into percentage by using this formula.

Table No. 1 Scoring for Level of Knowledge

\begin{tabular}{|l|l|}
\hline Poor & $0-40 \%$ \\
\hline Average & $41-60 \%$ \\
\hline Good & $61-74 \%$ \\
\hline Very good & $75 \%$ above \\
\hline
\end{tabular}

\section{Reliability of the Tool}

The reliability of measuring instrument is a major criterion for assessing its quality and adequacy. It is the ability of the instrument to consistently measure what it intends to measure, the extent to which the random variation influences consistency, stability and dependability of the results. The reliability of tool is elicited by test retest method. A sample of 10 middle class students are chosen and interviewed twice with a gap of one week the obtained data was subjected for the calculation of correlation coefficient and Karl Pearson's ' $r$ ' is found to be 0.81 . It indicates the tool is reliable and feasible the computation of ' $r$ ' was given in appendix

\section{Data collection procedure}

Prior to the actual data collection, written permission was obtained from the higher authorities and students. Data collection was carried out in two and information booklet was distributed among students. The researcher herself collected the data from the subject and data collected within a given period from 2007-2019 to 05-08-19. Data were collected from 100 students studying in middle school. Who fulfill the inclusion and exclusion criteria. 


\section{Objectives of the study:}

1. To assess the knowledge regarding malaria and it's prevention among students studying in selected middle school.

2. To find out any association between knowledge score and selected demographical variables.

\section{Organization of findings:}

The data obtained was analysis and presented in 3 different sections:

Section I: Description of demographic variables of middle school students.

Section II: Analysis of existing knowledge score of middle school students .

Section III: Association between knowledge regarding malaria and its prevention and demographic variables.

\section{Table -1}

Distribution of students studying in selection middle school according $\mathbf{N}$ 100

\begin{tabular}{|c|c|c|c|}
\hline S.NO & Demographic variable & $\begin{array}{l}\text { Freq } \\
\text { uency }\end{array}$ & $\begin{array}{l}\text { Percent } \\
\text { age } \%\end{array}$ \\
\hline 1 & $\begin{array}{l}\text { Age in year } \\
\text { A) } 10-11 \text { year } \\
\text { B) } 11-12 \text { year } \\
\text { C) } 12-13 \text { year } \\
\text { D) }>13 \text { year }\end{array}$ & $\begin{array}{l}37 \\
33 \\
16 \\
14\end{array}$ & $\begin{array}{l}37.0 \\
33.0 \\
16.0 \\
14.0\end{array}$ \\
\hline 2 & $\begin{array}{l}\text { Gender } \\
\text { A) Male } \\
\text { B) Female }\end{array}$ & $\begin{array}{l}55 \\
45\end{array}$ & $\begin{array}{l}55.0 \\
45.0\end{array}$ \\
\hline 3 & $\begin{array}{l}\text { Family } \\
\text { A) Nuclear family } \\
\text { B) Joint family } \\
\text { C) Extended }\end{array}$ & $\begin{array}{l}41 \\
35 \\
24\end{array}$ & $\begin{array}{l}41.0 \\
35.0 \\
24.0\end{array}$ \\
\hline 4 & $\begin{array}{l}\text { Religion } \\
\text { a) Hindu } \\
\text { b) Muslim } \\
\text { c) Christian } \\
\text { d) Other }\end{array}$ & $\begin{array}{l}52 \\
33 \\
10 \\
5\end{array}$ & $\begin{array}{l}52.0 \\
33.0 \\
10.0 \\
5.0\end{array}$ \\
\hline 5 & $\begin{array}{l}\text { Education of mothers } \\
\text { A) Non-formal education } \\
\text { B) Primary education } \\
\text { C) Secondary education } \\
\text { D) Senior Secondary }\end{array}$ & $\begin{array}{l}54 \\
15 \\
10 \\
21\end{array}$ & $\begin{array}{l}54.0 \\
15.0 \\
10.0 \\
21.0\end{array}$ \\
\hline 6 & $\begin{array}{l}\text { Occupation of father } \\
\text { a) Private employee } \\
\text { b) Business } \\
\text { c) Govt. employee } \\
\text { d) farmer }\end{array}$ & $\begin{array}{l}33 \\
29 \\
27 \\
11\end{array}$ & $\begin{array}{l}33.0 \\
29.0 \\
27.0 \\
11.0\end{array}$ \\
\hline 7 & $\begin{array}{l}\text { Any case of malaria in family or } \\
\text { neighbourhoods } \\
\text { A) Yes } \\
\text { B) NO }\end{array}$ & $\begin{array}{l}53 \\
47\end{array}$ & $\begin{array}{l}53.0 \\
47.0\end{array}$ \\
\hline 8 & $\begin{array}{l}\text { Any previous knowledge regarding } \\
\text { malaria } \\
\text { A) Yes } \\
\text { B) No }\end{array}$ & $\begin{array}{l}58 \\
42\end{array}$ & $\begin{array}{l}58.0 \\
42.0\end{array}$ \\
\hline
\end{tabular}




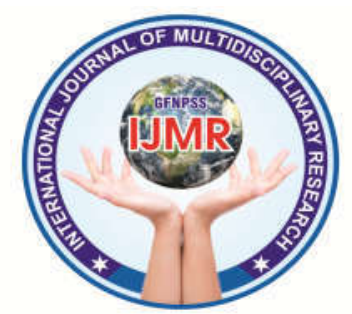

Section II: Analysis of knowledge level of the students studying in selected middle school regarding malaria and it's prevention

Part A : level of knowledge of students studying in selected middle school regarding malaria and it's prevention

In order to find out the level of knowledge middle school students .a four point scale was used .The percentage score were graded arbitrarily as follows 0 -40 poor knowledge 41 -6o average knowledge 61 - 74 good knowledge and above 75 very good knowledge .

\section{Table -2}

Assessment of knowledge of students studying in selected middle school regarding malaria and it's prevention $\mathrm{N}=100$

\begin{tabular}{|l|l|l|l|}
\hline Level of knowledge & Score & $\begin{array}{l}\text { Freque } \\
\text { ncy(f) }\end{array}$ & $\begin{array}{l}\text { Percent } \\
\text { age(\%) }\end{array}$ \\
\hline Poor $40 \%$ & $0-40 \%$ & 33 & 33.0 \\
\hline Average 41-60\% & $\begin{array}{l}41-60 \\
\%\end{array}$ & 23 & 23.0 \\
\hline Good 61-74\% & $61-74 \%$ & 21 & 21.0 \\
\hline Very good 75\% & $\begin{array}{l}\text { Above } \\
75 \%\end{array}$ & 23 & 23.0 \\
\hline Total & & 100 & 100.0 \\
\hline
\end{tabular}

Assessment of the level of knowledge of students studying in selected middle school regarding malaria and it's prevention shows that $33 \%$ of students have poor knowledge ,23\% have average knowledge , 21\% have good knowledge and $23 \%$ very good.

\section{CONCLUSION}

The main reason for high infant mortality rate in india is due to reason that women are not much aware about the facilities which are initiated by the government related to health. Many women are utilizing or consuming the health facilities but the percentage of the women who are not receiving these type of health facilities are high.

Today, nurse and midwives have an important role in health promotion, bring the health care manufactures. The midwife is posed to a unique function of identifying and providing huge standard of malaria and its prevention that contributes to the maintenance of good health and minimize the severity of the communicable diseases.

\section{Recommendation:}

Based upon the findings of the study, following recommendations were made for further study:

- Similar studies can be conduct in community setting.

- A similar study can be conducted on a large sample. 


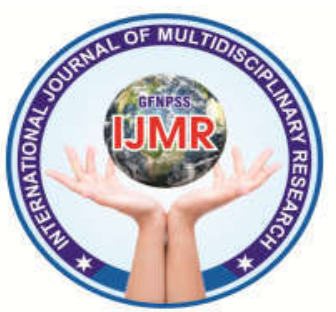

- A comparative study can be done

3. History of malaria \{online between rural and urban middle school students .

URL:http://www nvbdcp/historical perspective.htm

- An experimental study can be conducted using control and experimental group.

- Follow-up study can be conducted to evaluate the effectiveness of information booklet.

4. Park, J.E. Park, Text Book of Preventive and Social Medicine. Eighteenth edition New Delhi, Banarsidas Bhanot Publishers 2005.

5. S.N. Huda, T. Shahab, S.M. Ali, K. Afzal. A comparative Clinical Trial in Children with Severe Malaria. Indian pediatrics. 2003 Oct; 40:989.

\section{BIBLIOGRAPHY}

1. Suneel Garg, Anita Nath, current status of national rural health mission journey of community medicine, 2007 may and summary

of the budget $2006-07$ available from; http/www.india .now.org

2. Basavanthappa BT community health nursing $1^{\text {st }}$ edition new Delhi : Jaypee Brother :1998

6. V.V.R.Seshubabu.Review in community medicine. Paras publications. Second edition.New Delhi. 1996; 273 - 278.

7. www.Malaria site .org

8. Guidelines for the treatment of malaria .who library cataloguing in publication data. WHO/HTM/MAL /2006.1108.

9. www.Malaria site .org 